\title{
Corrosion Analysis in the Electronics Industry of Mexicali Influenced by Atmospheric Factors
}

\author{
http://dx.doi.org/10.3991/ijes.v2i4.4096 \\ Gustavo López Badilla, María Marcela Acosta Gómez, \\ Heriberto Montoya Gonzalez, Julio Cesar Castillo Moreno \\ Instituto Tecnológico de Mexicali, Mexicali, B.C., México
}

\begin{abstract}
The generation of aggressive environments in indoor of the electronics industry is concerned to people of the electronics industry of Mexicali. This is influenced by variations of relative humidity and temperature as the most important climatic parameters added to the concentration levels of sulfurs in indoor of industrial plants of this arid zone of the northwest of Mexico. For this reason a study was made determine by a correlation analysis the indices of the climatic and pollution factors to prevent the generation of the corrosion phenomena. This is significant to reduce the bad function of electronic devices and systems in this zone of Mexico. The study was made from July of 2013 to June 2014.
\end{abstract}

Index Terms-Electronics industry, atmospheric factors, corrosion, electrical failures.

\section{INTRODUCTION}

The fast growth of the electronics industry in the past fifty years, has contributed to their economic progress of each area or the world. Being Mexicali a border city with United States is an important zone of Mexico, where are a lot companies, where the majorly are of the electronics industry. Both summer and winter, relative humidity and temperature are extremes. This originate the formation of a thin layer sometimes visible and other times not, promoting the corrosion phenomena and then the deterioration of the metallic surfaces of electrical connections of connectors of industrial electronics equipments and machinery decreasing their operation yielding. This this occurs in Mexicali, even in clean rooms where are purifiers and air exchangers and specialized filters to finite particle and polluted gases to avoid generation of aggressive environments and thus the corrosion process. The variations of climate in indoors of electronic plants, is due to the variation of humidity, temperature, solar radiation, concentration of air pollutants such as derivate of sulfur principally as $\mathrm{SO}_{2}$ and $\mathrm{H}_{2} \mathrm{~S}$, and $\mathrm{NO}_{\mathrm{X}}$ and solid particles $\mathrm{Pm}_{2.5}$ and $\mathrm{Pm}_{10}$.

\section{A. Atmospheric corrosion}

The air pollutants and solid particles are monitored by the Environmental Monitoring Stations (EMS) in Mexicali. Electronic equipment installed inside the plants are fitted with copper components since they exhibit electrical and thermal conductivity. With the deterioration of copper, the equipment functionality decreases, fail and originates economic losses. This equipment is exposed to a wide range of indoor aggressive environments causing corrosion damage. The metallic materials used in electronic devices are susceptible to corrosion and indoor deterioration: by sulfides at low and high humidity and at time of wetness (TOW) that form a thin layer of water on the metallic surface. Corrosion in electronics systems causes severe damage, leading to electrical failures. The electronics equipment suffers from corrosion, as humidity levels, sources emitting pollutants such as $\mathrm{CO}, \mathrm{NO}_{\mathrm{X}}$ and sulfides penetrate thought cracks or air conditioning systems. Corrosion phenomena affect connections of electronic equipment (Frankel, 1995) and other electronics components protected with plastic or metallic materials. Atmospheric corrosion is an electrochemical phenomenon that occurs in the wet film formed on metal surfaces by climatic factors (Table I).

TABLE I.

CLIMATIC FACTORS AND THEIR MEASUREMENT

\begin{tabular}{|l|l|l|}
\hline \multicolumn{1}{|c|}{ Factors } & \multicolumn{1}{c|}{ Measuring instrument } & \multicolumn{1}{c|}{ Unit } \\
\hline Humidity & Hygrometer & $\%$ \\
\hline Temperature & Thermometer & $\circ \mathrm{C}$ \\
\hline Atmospheric pressure & Barometer & $\mathrm{mmHg}$ \\
\hline Solar radiation & Pyranometer & $\mathrm{W} / \mathrm{m}^{2}$ \\
\hline Pluvial precipitation & Rain gauge & $\mathrm{Mm}$ \\
\hline Wind direction & Wind vane & $\circ \mathrm{Grade}$ \\
\hline Wind speed & Anemometer & $\mathrm{m} / \mathrm{seg}$ \\
\hline
\end{tabular}

\section{B. Factors causing corrosion}

The levels of RH and temperature higher of $70 \%$ and 35 ${ }^{\circ} \mathrm{C}$, are the principal factor of the corrosion and increases the corrosion rate $(\mathrm{CR})$, and this climatic parameters, generates a higher valence change in the state of the active metals, damaging the metals very fast (Lopez G. et al, 2010). This occurs when the oxide film s formed on the surface of $\mathrm{Cu}$, are not covered uniformly, and are covered only in some zones of the $\mathrm{Cu}$ surface, causing the pitting corrosion. The levels of $\mathrm{SO}_{\mathrm{X}}$ generated by $\mathrm{H}_{2} \mathrm{~S}$ in some periods of the year in Mexicali overpass the air quality standards. The corrosion products form dendrites or whiskers in the metallic joints and connectors (Nishikata, et al 1995, Nishimura et al, 2000). There are obvious differences in outdoor and indoor environments and consequent differences between outdoor and indoor corrosion behavior (Lyon et al, 1996). The corrosion of metals as copper in indoor environments may be viewed as a variation of outdoor atmospheric corrosion. In contrast to outdoor exposure, in an indoor environment the wet film on the metal surface is thinner and it is often governed by relatively constant controlled humidity conditions (Veleva et al, 2008).

\section{Environmental pollution}

This is very important, as atmospheric studies based on analytical chemistry techniques and high software that 


\section{SHORT PAPER}

CORROSION ANALYSIS IN THE ELECTRONICS INDUSTRY OF MEXICALI INFLUENCED BY ATMOSPHERIC FACTORS

determine the composition of the atmosphere and, the effect of corrosivity levels (CL) in indoors and outdoors of the food industry. The alteration of the climate, contributes to the CR [16]; the calculation indicates that most of these substances are present in the atmosphere at levels higher than expected in thermodynamic equilibrium with nitrogen, oxygen, carbon dioxide and water vapor. The composition of this atmospheric pollution is controlled by a series of kinetic mechanisms and encompasses a complex combination of chemical, physical and biological agents [17].

\section{Operation of electronic systems}

The efficiency of an industrial operation is based on productivity in the industrial plants, and the main features that show the efficiency of a manufactured product are their good appearance, low cost, ease of operation and safe (Samuels, 2003). The electronic devices and equipments used in warehouses, production and shipping areas are exposed to environmental factors in indoor of industrial plants, influenced by the outdoor atmospheres (Lopez G., 2008). The climatic factors such as relative humidity $(\mathrm{RH})$ and temperature in combination with sulfates, affects the operation of the electronic systems.

\section{Methodology}

Metallic specimens for corrosion testing were exposed in indoors of electronics plants for a period of one year in Mexicali. The specimens corrosion was evaluated applying the gravimetric method with the ASTM standards G 1 , $\mathrm{G} 4, \mathrm{G} 31$ [5], and correlated with the minimum, average and maximum outdoor $\mathrm{RH}$ and temperature parameters in different seasonal periods with TOW analysis too [6].

\section{A. Gravimetric analysis}

In Mexicali, an arid zone, the electronic plants are located in industrial parks Rectangular specimens with dimensions of $2.5 \mathrm{~cm} . \times 1 \mathrm{~cm} . \times 0.5 \mathrm{~cm}$. are cleaned with high purity isopropyl alcohol in ultrasound for 15 minutes. Immediately after cleaning the copper probes are placed in hermetically sealed plastic bags, ready to be installed in industrial plants. After each exposure period the specimens were removed, weighed and cleaned to obtain the weight loss and the corrosion rates (CR) [7]. The corrosion products morphology was examined with an optical microscope. The gaseous pollutants mentioned above cause deterioration of metals used in electronics devices [8].

\section{B. Atmospheric factors}

The electronics equipment suffers from corrosion, at high humidity levels. Air pollutants such as $\mathrm{CO}, \mathrm{NO}_{\mathrm{X}}$ and sulfides penetrate through defects of the air conditioning systems. Corrosion phenomena affect connections of electronic equipment and other electronics components protected with plastic or metallic materials [6]. Atmospheric corrosion is an electrochemical phenomenon that occurs in the wet film formed on metal surfaces by climatic factors.

\section{Corrosivity analysis}

The classification of the corrosivity categories according to TOW was established according to standards ISO 9223, ISO 9224, ISO 9225, ISO 9226, ISO 1184-1 and ISO 1184-2 (Table II). The deterioration of the metal spec- imens was evaluated by the gravimetric method; it was correlated with the minimum, average and maximum $\mathrm{RH}$ and outdoor temperature in different seasonal periods, which affect the indoor climate plants.

\section{Thermography measurements}

A portable thermograph PCE-HT 110 was used to monitoring directly the temperature in the cooper probes to determine instantly the temperature in the specimens evaluated. This was very important to know the kinetic process of the corrosion phenomena in the industrial plant where was made the study and take actions rapidly to prevent the presence of corrosion. Also the metallic probes were evaluated by the microscopy technique as Scanning Electron Microscopy (SEM) Technology LTD IP12 2TW to determine the air pollutants that react with the metallic surface exposed in the manufacturing process of the electronics industry. The quantitative and qualitative chemical analysis information was obtained using the energy disperse $x$-ray (EDS) with the SEM [25]. The images in SEM were created by the incident beam of electrons in the raster pattern of the sample's surface.

\section{RESULTS}

Corrosion analysis was made in cooper probes exposed at the periods mentioned. The evaluations of gravimetric analysis are showed in table III.

The corrosion rate was measured by the mass loss compared with the initial mass of the copper corrosion. Then, was obtained the corrosivity levels (CL) measuring the indoor in manufacturing process of the company and classifying as aggressive or no aggressive environments. With this information was determine the velocity of deterioration of the copper probes and then the metallic surfaces of the electrical connections and connectors of the electronic systems. This is showed in table IV in according to the ISO XXX.

TABLE II.

LEVEL CATEGORIES OF TIME OF WETNESS IN METALS

\begin{tabular}{|c|c|}
\hline Categories $\left({ }^{\mathbf{a}}\right)$ & TOW $(\mathbf{b}), \mathbf{h} / \mathbf{y e a r}$ \\
\hline$\tau_{1}$ & $\leq 10$ \\
\hline$\tau_{2}$ & 10 to 250 \\
\hline$\tau_{3}$ & 250 to 2500 \\
\hline$\tau_{4}$ & 2500 to 5500 \\
\hline$\tau_{5}$ & $>5500$ \\
\hline
\end{tabular}

Source. Environmental Deterioration of Materials, A. Moncmanova, WIT Press, 2007. ${ }^{\text {a }}$ According to ISO 9223. ${ }^{\mathrm{b}}$ TOW. time of wetness; RH $80 \%$, Temp $>0{ }^{\circ} \mathrm{C}$.

TABLE III.

CORROSION RATE OF COOPER PROBES

\begin{tabular}{|c|c|c|}
\hline Metallic probes & Month & Corrosion rate, $\mathbf{m g . m ^ { 3 }}$ /year \\
\hline $\mathrm{C}_{1}$ & 1 & 98 \\
\hline $\mathrm{C}_{2}$ & 3 & 112 \\
\hline $\mathrm{C}_{3}$ & 6 & 146 \\
\hline $\mathrm{C}_{4}$ & 12 & 202 \\
\hline
\end{tabular}

Period of study from July 2013 to June 2014 
TABLE IV.

CORROSVITY LEVESL IN INDOOR OF THE COMPANY

\begin{tabular}{|c|c|}
\hline Month & CL \\
\hline 1 & 1 \\
\hline 3 & 1 \\
\hline 6 & 2 \\
\hline 12 & 3 \\
\hline
\end{tabular}

Period of study from July 2013 to June 2014

Also, was made the thermography and SEM analysis to determine rapidly the kinetic process and causes of the corrosion in the company evaluated as shows in figures 1 and 2

In figures 1 and 2 were observed the temperature with the thermography technique in the left side. In this side, in the bottom (orange and orange-yellow zones) were presented the regions with less damage by the corrosion, but can generates electrical failures in the electronic systems. And the zones with black and orange are corroded with more deterioration and can break the electrical conductivity and originate serious problems in the electronics systems used in the electronics industry of Mexicali city. Also, the SEM analysis was made to know the effect of the deterioration at microscale as showed in the right side of each figure.

\section{CONCLUSIONS}

All the metallic probes used in the study that are utilized in the electronics industry of Mexicali, in the manufacturing process, were deteriorated by the atmospheric corrosion after one year of exposure. Sulfide was the main component in the corrosion products, due the presence of $\mathrm{SO}_{2}$ and $\mathrm{H}_{2} \mathrm{~S}$, emitted principally by human activities and the geothermal field of Cerro Prieto, which promotes the contamination of indoor places of the electronics industry. Carbon steel, copper, nickel, silver and tin exposed to air pollutants reveal that an increase on their concentrations of outdoor conditions that penetrate to indoor areas of industrial plants. This was a negative effect in their metallic surfaces. Long periods with $\mathrm{RH}$ values higher than $75 \%$ and concentration of pollutants up to regulations of air quality standards, promoted the corrosion of the metals mentioned above.

\section{ACKNOWLEDGMENTS}

The authors express their gratitude to the company and people that help to the researching group of the Instituto Tenológico de Mexicali.

\section{REFERENCES}

[1] Nishimura T., Katayama H., Noda K. and Kodama T.; Effect of $\mathrm{Co}$ and $\mathrm{Ni}$ on the corrosion behaviour of low alloys steels in wetdry environments; Corrosion Science, 2000. http://dx.doi.org/10.1016/S0010-938X(00)00018-4

[2] L. Veleva, B. Valdez, G. Lopez, L. Vargas and J. Flores; Atmospheric corrosion of electro-electronics metals in urban desert simulated indoor environment; Corrosion Engineering Science and Technology; 2008. http://dx.doi.org/10.1179/17432780 $\underline{8 X 286275}$

[3] Annual Book of ASTM Standards G 1, Practice for preparing, cleaning and evaluation corrosion test specimens.

[4] ISO 9223:1992, Corrosion of metals and alloys, Corrosivity of Atmospheres, Classification.

[5] ISO 11844 PART 1. Corrosion of metals and alloys- Classification of low corrosivity of indoor atmospheres- Determination and estimation of indoor corrosivity.
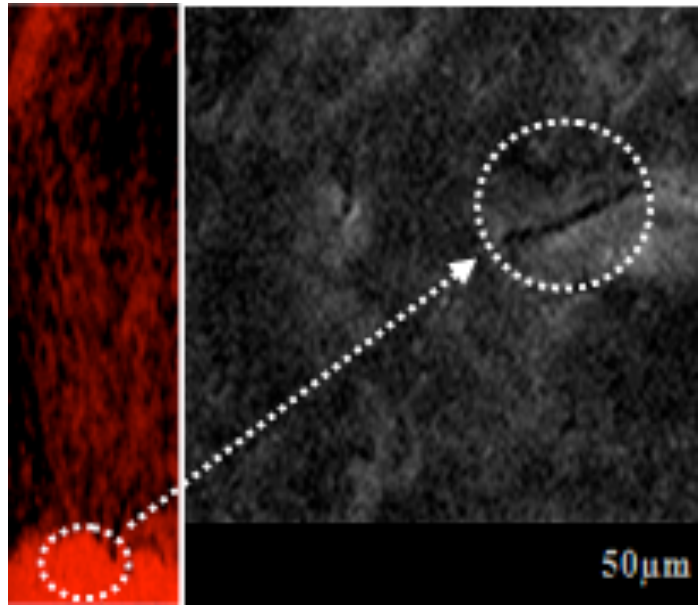

Figure 1. Analysis of copper corrosion in March 2014 with: (a) thermography and (b) SEM techniques

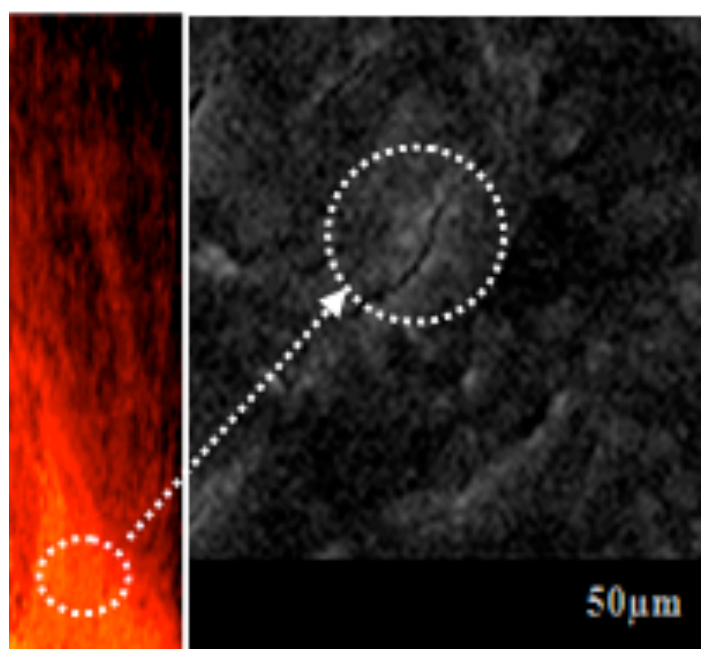

Figure 2. Analysis of copper corrosion in June 2014 with: (a) thermography and (b) SEM techniques

[6] Lopez B.G.,. Valdez S.B,. Zlatev K.R, Flores P.J,.. Carrillo B.M and. Schorr W.M; Corrosion of metals at indoor conditions in the electronics manufacturing industry; Anti-Corrosion Methods and Materials; 2007. http://dx.doi.org/10.1108/00035590710833510

[7] López Badilla Gustavo; Ph.D. Thesis; Caracterización de la corrosión en materiales metálicos de la industria electrónica en Mexicali, B.C., 2008 (Spanish).

[8] Lopez G., Valdez B. and Schorr M.; Influence of climate factors on copper corrosion in electronic equipment and devices; Symposium 16: NACE "Corrosion and Metallurgy"; IMRC 2009, Cancun, Mexico (Spanish).

[9] Moncmanova A.; Environmental Deterioration of Materials, Ed. WIT Press, 2007, pp 108-112. http://dx.doi.org/10.2495/978-184564-032-3

[10] Zlatev R., Valdez B., Stoycheva M., Vargas L., Lopez G., Schorr M.; Symposium 16: NACE "Corrosion and Metallurgy"; IMRC 2009, Cancun, Mexico.

\section{AUTHORS}

Gustavo López Badilla, María Marcela Acosta Gómez, Heriberto Montoya Gonzalez, and Julio Cesar Castillo Moreno are with the Instituto Tecnológico de Mexicali, Mexicali, B.C., México.

The financial support for this investigation was sponsored by the Dirección General de Educación Superior y Tecnológica (DGEST) and the Instituto Tenológico de Mexicali in Mexicali, B.C., Mexico with the project DGEST: MEX-IMCT-IQ-0000-000. Submitted 02 August 2014. Published as resubmitted by the authors 25 October 2014. 